\title{
TNM Ovary Neoplasm Staging
}

National Cancer Institute

\section{Source}

National Cancer Institute. TNM Ovary Neoplasm Staging. NCI Thesaurus. Code C18008.

A system for specific evaluation of tumors of the ovaries. 